\title{
LA SUSTITUCIÓN TECNOLÓGICA DE TRABAJADORES HUELGUISTAS ${ }^{1}$
}

\author{
Francisco Andrés Valle Muñoz ${ }^{2}$ \\ Profesor Titular de Derecho del Trabajo y de la Seguridad Social \\ Acreditado a Catedrático de Universidad \\ Universidad Pompeu Fabra, Barcelona
}

\begin{abstract}
El recurso empresarial a medios tecnológicos para sustituir a trabajadores durante una huelga ha puesto de manifiesto el conflicto permanente que existe entre capital y trabajo, y ha provocado un debate doctrinal y jurisprudencial sobre esta materia. Ante la inexistencia de una regulación legal sobre el tema, la doctrina científica y la jurisprudencia ordinaria y constitucional han defendido argumentos contradictorios, dejando la cuestión abierta o sin resolver. En el presente estudio llegamos a la conclusión que el empresario no puede impedir la eficacia del derecho de huelga sustituyendo a los trabajadores huelguistas mediante instrumentos tecnológicos, y por tanto, desde un punto de vista jurídico-laboral, debiera prohibirse la sustitución tecnológica de trabajadores huelguistas.
\end{abstract}

The business use of technological means to replace striking workers has evidenced the permanent conflict that exists between capital and labor and has provoked a doctrinal and jurisprudential debate on this matter. In the absence of a legal regulation on the subject, scientific doctrine and ordinary and constitutional jurisprudence, have defended contradictory arguments, leaving the question unresolved. In the present study we conclude that the employer can't avoid the effectiveness of the right to strike, replacing striking workers through technological means, and therefore, from a legallabor point of view, the technological substitution of workers should be prohibited.

Title: The technological replacement of striking workers

Palabras clave: huelga; sustitución; tecnología; trabajadores huelguistas.

Keywords: strike; replacement; technology; striking workers.

IUSLabor 3/2018, ISSN 1699-2938, pp 187-216

DOI. 10.31009/IUSLabor.2018.i03.05

\footnotetext{
${ }^{1}$ Comunicación presentada en las XXIX Jornadas Catalanas de Derecho Social, que con el título: "Nuevas Tecnologías y Relaciones Laborales" se celebraron en Barcelona los días 8 y 9 de marzo de 2018.

${ }^{2}$ Miembro del grupo de investigación consolidado reconocido por la Generalitat de Cataluña: "Social and Business Research Laboratory" (SBRLab). Ref. 2017 SGR 1572.
} 


\section{Sumario}

1. Aproximación normativa y conceptual al "esquirolaje" tecnológico

2. Las tesis prohibitivas del "esquirolaje" tecnológico

3. Las tesis permisivas del "esquirolaje" tecnológico

4. Conclusiones 


\section{Aproximación normativa y conceptual al "esquirolaje" tecnológico}

El artículo 6.5 del Real Decreto Ley 17/1977 de 4 de marzo sobre Relaciones de Trabajo (en adelante RDLRT), señala que: "[e]n tanto dure la huelga, el empresario no podrá sustituir a los huelguistas por trabajadores que no estuviesen vinculados a la empresa al tiempo de ser comunicada la misma, salvo caso de incumplimiento de las obligaciones contenidas en el apartado número siete de este artículo".

Mediante dicho precepto se pretende preservar la eficacia del ejercicio del derecho de huelga $^{3}$, que se vería drásticamente mermada de permitirse al empresario la contratación de trabajadores externos para sustituir a los huelguistas, en lo que se conoce comúnmente como "esquirolaje". Tan solo se permite la sustitución de trabajadores huelguistas en caso de incumplimiento de los servicios de mantenimiento y de seguridad, pero también en caso de incumplimiento de los servicios mínimos, como ha declarado la jurisprudencia constitucional ${ }^{4}$ y la propia doctrina científica ${ }^{5}$.

Sin embargo, la norma no contempla lo que ha dado en llamarse "sustitución técnica", "esquirolaje tecnológico", o "esquirolaje virtual"6. El "esquirolaje" tecnológico podría definirse como la utilización por parte del empresario de los medios técnicos que tiene a su disposición para continuar con su actividad productiva durante el desarrollo de una huelga ${ }^{7}$. En este caso, no se trata de sustituir a los trabajadores huelguistas mediante mano de obra externa, o mediante la movilización de los propios trabajadores de la empresa que no han secundado el paro, sino que la actividad de los huelguistas es suplida mediante recursos de índole técnica. Se trata de una forma de "esquirolaje" problemática por los inconvenientes que presenta su delimitación conceptual, y que guarda cierta relación con el "esquirolaje" interno, dado que el empresario no hace uso de recursos externos a la empresa.

\footnotetext{
${ }^{3}$ VALDEOLIVAS GARCÍA, Y., Antisindicalidad y relaciones de trabajo (Un estudio de la conducta antisindical en la empresa), ed. Civitas. Madrid, 1994, p. 379.

${ }^{4} \mathrm{STC}^{\circ}{ }^{\circ} 33 / 2011$, de 28 de marzo y STC n ${ }^{\circ} 17 / 2017$, de 2 de febrero.

${ }^{5}$ GARCÍA NINET, I., GARCÍA VIÑA, J., "Algunas consideraciones acerca del esquirolaje interno y externo, así como sobre ciertas medidas empresariales (algunas curiosas) para reducir los efectos de la huelga", Aranzadi Social no 5, 1997, p. 645 y ss.; SANTIAGO REDONDO, KM., "Jurisprudencia constitucional. Pronunciamientos del Tribunal Constitucional: sustitución de trabajadores huelguistas y protección reforzada de los miembros del comité de huelga", Relaciones laborales: Revista crítica de teoría y práctica, $\mathrm{n}^{\circ}$ 21-22, 2012, p. 107.

${ }^{6}$ SIRVENT HERNANDEZ, N., "La vulneración empresarial del derecho de huelga y responsabilidad por daños y perjuicios", Temas Laborales, $\mathrm{n}^{\circ}$ 128, 2015, p. 147.

${ }^{7}$ Por todos: TALENS VISCONTI, E., "Esquirolaje tecnológico: Interrogantes abiertos", Revista Doctrinal Aranzadi Social, vol. 6, nº 5, 2013, p. 186.
} 
En el actual proceso de evolución tecnológica en el que estamos inmersos, la sustitución "virtual" de trabajadores huelguistas por máquinas capaces de realizar total o parcialmente las funciones de éstos, conduce a reflexionar sobre el papel que debe ocupar el derecho de huelga ${ }^{8}$, y es que supuestos como el descrito pueden arrebatar a la misma su capacidad de repercutir negativamente en la actividad empresarial e incluso privarla de su eficacia simbólica o mediática, lo que en las sociedades contemporáneas es tanto como condenarla a su inexistencia ${ }^{9}$.

Para poder entender este fenómeno hay que partir de la base de que el alto nivel de tecnificación existente en ciertos sectores productivos permite al empresario reducir al mínimo la necesidad de emplear mano de obra durante el proceso de producción, pudiendo incluso llegar a suprimirse íntegramente (aunque sea de manera temporal) la participación de los trabajadores en el mismo ${ }^{10}$. Ello supone que la actividad empresarial puede mantenerse sin la más mínima intervención de los trabajadores, y de manera casi imperceptible para los usuarios o clientes ${ }^{11}$. Siendo ello así, para que pueda apreciarse una situación de "esquirolaje" tecnológico, resulta necesaria la concurrencia de dos requisitos:

En primer lugar, que la huelga tenga lugar en empresas que dispongan de medios tecnológicos a su alcance, pudiendo diferenciarse tres tipos de empresas ${ }^{12}$ : aquellas que tan sólo emplean mano de obra y no medios tecnológicos; aquellas que combinan medios tecnológicos con mano de obra; y aquellas que emplean exclusivamente medios tecnológicos limitándose al mínimo la intervención humana. Es en el segundo y tercer supuesto donde la sustitución tecnológica de los trabajadores huelguistas resultará más

\footnotetext{
${ }^{8}$ MARTIN JIMENEZ, R., "Sustitución virtual de trabajadores en huelga", Relaciones Laborales $\mathrm{n}^{\circ}$ 1, Tomo 1, 2000, p. 797 y ss.

${ }^{9}$ PEREZ REY, J., "El esquirolaje tecnológico: un importante cambio de rumbo de la doctrina del Tribunal Supremo (STS de 5 de diciembre de 2012)", Revista de Derecho Social, no 61, 2013, p. 164; VAZQUEZ, A., "Validez del "esquirolaje tecnológico" en situaciones de huelga", Observatorio de recursos humanos y relaciones laborales $\mathrm{n}^{\circ}$ 122, 2017, p. 74 y ss.; PEDRAJAS MORENO, A., "El esquirolaje tecnológico", Observatorio de recursos humanos y relaciones laborales, n 105, 2015, p. 66 y ss.

${ }^{10}$ TORRENTE GARI, S., "El derecho de huelga y las innovaciones tecnológicas", Revista Española de Derecho del Trabajo, $\mathrm{n}^{\circ}$ 102, 2000, p. 447 y ss.

${ }^{11}$ MORALO GALLEGO, S., "El ejercicio del derecho de huelga y el impacto de las nuevas tecnologías y la descentralización productiva", en AA.VV. Derecho colectivo, ed. CGPJ, Madrid, 2003, p. 218; TALENS VISCONTI, E., "Esquirolaje tecnológico: Interrogantes abiertos", ob. cit. p. 176.; PEREZ REY, J., "Tertulias, reportajes de actualidad y esquirolaje tecnológico en la huelga general. A propósito de la STS de 11 de junio de 2012", Revista de Derecho Social, nº 59, 2012, p. 197.

${ }^{12}$ TOSCANI GIMÉNEZ, D., "La prohibición de esquirolaje durante la huelga con especial mención al esquirolaje tecnológico", Trabajo y derecho: nueva revista de actualidad y relaciones laborales, $\mathrm{n}^{\mathrm{0}} 30$, 2017, p. 86; TODOLI SIGNES, A., "El esquirolaje tecnológico como método de defensa ante una huelga", Actualidad Laboral, no 7-8, 2014, p. 2 y ss.
} 
fácil por parte del empresario, pero también es en estos casos donde será más difícil apreciar la posible violación del derecho fundamental.

Es en el sector audiovisual y más concretamente el de la radiotelevisión, donde se han venido produciendo los principales conflictos relativos al "esquirolaje" tecnológico, tal y como demuestran los casos conocidos por la jurisprudencia. Pero no constituyen el único tipo de empresas donde estos comportamientos pueden acaecer. Otros sectores donde la capacidad tecnológica y la automatización de los procesos productivos son muy intensas, pueden perfectamente dar lugar a formas de "esquirolaje" tecnológico. Así sucede en empresas de telecomunicaciones (y en especial de telefonía), en empresas del sector bancario, o en ciertas cadenas de montaje ${ }^{13}$, las cuales pueden sostener su actividad productiva durante la huelga sin la más mínima participación de los trabajadores, tan sólo programando sus sistemas con antelación para que, de forma automatizada y con total precisión en el tiempo, puedan ponerse en funcionamiento mientas se mantiene la huelga, y consiguiendo con ello minimizar los efectos del paro.

En segundo lugar, para que el recurso empresarial a los instrumentos técnicos durante la huelga pueda considerarse incompatible con ésta, es preceptivo que consiga privar materialmente a los trabajadores de su derecho fundamental, vaciando su contenido esencial, o minorando la presión asociada a su ejercicio. Ello impone, según la doctrina científica $^{14}$, que la actuación empresarial interfiera en la eficacia del derecho de huelga, y por tanto, un dato a tener en cuenta será el alcance que la sustitución técnica de los trabajadores huelguistas haya podido tener en la normal continuidad de la actividad productiva, y si ha podido o no paliar las previsibles pérdidas derivadas de la huelga ${ }^{15}$, en una adecuada ponderación de los sacrificios que provoca la misma.

El origen de esta problemática se encuentra en la ausencia de referencias legales a la sustitución tecnológica de trabajadores huelguistas en una norma como es el RDLRT 17/1977 de 4 de marzo, que fue promulgada en una época en la que el debate de las nuevas tecnologías de la información y de la comunicación aún no estaba presente. Se trata de una norma obsoleta, que partía de la base de que la huelga no repercutía más que en los poderes empresariales de contratación durante el conflicto (prohibición del "esquirolaje" externo) y de que la oposición empresarial a la huelga se producía

\footnotetext{
${ }^{13}$ BAYLOS GRAU, A., "Continuidad de la producción o del servicio y facultades empresariales en casos de huelga”, en AA.VV. Estudios sobre la huelga, ed. Bomarzo, Albacete, 2005, p. 104.

14 PEREZ REY, J., "El esquirolaje tecnológico: un importante cambio de rumbo de la doctrina del Tribunal Supremo (STS de 5 de diciembre de 2012)”, ob. cit. p. 173.

${ }^{15}$ TALENS VISCONTI, E., "Esquirolaje tecnológico: Interrogantes abiertos”, ob. cit. p. 176.
} 
clásicamente a través del cierre patronal, premisas que resultan ampliamente desbordadas en la actualidad ${ }^{16}$.

Pero lo cierto es que ni siquiera el artículo 18.3 del Proyecto de Ley Orgánica de Huelga de 1993, preveía en su momento la prohibición del "esquirolaje" tecnológico, por lo que habrá que esperar a lo que disponga una futura Ley Orgánica reguladora del derecho de huelga. Por otra parte, la negociación colectiva tampoco ha regulado el tema en profundidad, de modo que ha sido la jurisprudencia la que ha sentado las líneas de actuación en esta materia.

La insuficiencia normativa existente conduce a que el tratamiento jurídico del "esquirolaje", al igual que el de la huelga, haya tenido que irse adaptando a golpe de sentencia judicial, abriéndose paso una importante interpretación "ex constitutione" de la norma preconstitucional, que ya señaló que las operaciones hermenéuticas que se realizasen sobre ella no podían refugiarse en la simpleza de la interpretación literal o a "sensu contrario", de la norma prohibitiva del "esquirolaje" externo, según la cual aquello que no está prohibido legalmente (como es el "esquirolaje" tecnológico), cabe entenderlo permitido ${ }^{17}$.

Ello ha llevado a la doctrina científica ${ }^{18}$ a afirmar que el denominado "esquirolaje" tecnológico, es una cuestión que permanece todavía abierta. O dicho de otro modo: no está cerrado el debate sobre la utilización por parte del empresario de medios tecnológicos para preservar la continuidad de la actividad productiva durante una huelga.

Buena muestra de que estamos ante un tema no zanjado, lo constituye el vaivén de la jurisprudencia constitucional y ordinaria sobre la materia, con pronunciamientos opuestos entre sí, y que nos permite diferenciar dos grandes tesis respecto al "esquirolaje" tecnológico: aquella que argumenta la prohibición del mismo, y la que defiende su permisión.

\section{Las tesis prohibitivas del "esquirolaje" tecnológico}

Los argumentos dirigidos a defender la prohibición del "esquirolaje" tecnológico, se encuentran básicamente en los siguientes pronunciamientos jurisprudenciales: por parte

\footnotetext{
${ }^{16}$ PEREZ REY, J., "El esquirolaje tecnológico: un importante cambio de rumbo de la doctrina del Tribunal Supremo (STS de 5 de diciembre de 2012)", ob. cit. p. 163.

${ }^{17}$ STC 123/1992, de 28 de septiembre, y STC 33/2011, de 28 de marzo, ambas relativas al "esquirolaje" interno.

${ }^{18}$ TALENS VISCONTI, E., “Esquirolaje tecnológico: Interrogantes abiertos”, ob. cit. p. 190.
} 
del Tribunal Constitucional, en las sentencias no 183/2006 y siguientes de 19 de junio, y en el voto particular a la STC $n^{\circ} 17 / 2017$, de 2 de febrero. Y por parte del Tribunal Supremo, en el voto particular a la sentencia de 11 de junio de 2012 y en la sentencia de 5 de diciembre de 2012. Interesa que nos detengamos en ellos.

En el año 2006 el Tribunal Constitucional fijó una doctrina ${ }^{19}$ a partir de su sentencia $\mathrm{n}^{\mathbf{o}}$ 183/2006 de 19 de junio, conforme a la cual, el empleo de determinados medios tecnológicos durante una huelga en una televisión pública, podría ser una práctica abusiva si se conseguía minimizar los efectos de la misma. El Tribunal Constitucional considera nulos, por vulnerar el derecho de huelga, los apartados del Real Decreto que desarrollaba el funcionamiento de los servicios mínimos durante una huelga, y que preveía la emisión, dentro de los horarios y canales habituales de difusión, de una programación previamente grabada, así como la producción y emisión de la normal programación informativa.

Según el Tribunal Constitucional, "la cuestión planteada es una cuestión de límites de un derecho fundamental, en la que, en la relación entre el derecho y su límite posible, el criterio de la interpretación debe ser el de mayor amplitud posible del derecho y la restricción del límite a lo necesario". Y continúa afirmando: "[n] c cabe duda de que el derecho de huelga, no es un derecho ilimitado y que la salvaguarda del derecho a comunicar y recibir información veraz por cualquier medio de difusión (art. 20.1 d) CE) puede operar como límite de aquel derecho a la hora de definir los servicios esenciales y los servicios mínimos en relación con una huelga concreta", pero siendo ello así, "no toda la programación de televisión tiene que ver con el referido derecho constitucional a la información, existiendo una gran porción de espacio de puro entretenimiento. Por ello, el resto de la plural actividad televisiva previamente grabada, desprovista de todo contenido e interés informativo, aún respaldada por un evidente interés legítimo tanto del comunicador como de los receptores, en nada concierne al derecho a comunicar y recibir información "ex" art. 20.1 d) CE, no invocándose en el Real Decreto impugnado ningún otro derecho o libertad constitucionalmente reconocido ni ningún bien de idéntica significación cuya preservación requiera el sacrificio del derecho de huelga para la emisión de la referida programación previamente grabada" ${ }^{20}$.

\footnotetext{
${ }^{19}$ Dichas sentencias pertenecen al grupo de las cuatro prácticamente idénticas (las 183/2006, 184/2006, 191/2006 y 193/2006) dictadas por el Tribunal Constitucional el 19 de junio de 2006 y referidas a los servicios mínimos declarados por el RD 531/2002 a raíz de la huelga general de 20 de junio de 2002, en las radios y televisiones (tanto públicas como privadas), y respondiendo con ello a sendos recursos de los sindicatos CCOO y UGT.

${ }^{20} \mathrm{STC} \mathrm{n}^{\mathrm{o}} 183 / 2006$, de 19 de junio.
} 
A las precedentes consideraciones ha de añadirse, que mediante la calificación como servicio mínimo de la emisión, dentro de los horarios habituales de difusión, de una programación previamente grabada "se persigue la no interrupción del servicio de la radiodifusión sonora y de la televisión, con lo que se priva de repercusión apreciable a la huelga, sustrayéndole su virtualidad de medio de presión y de inequívoca exteriorización de los efectos del paro laboral efectivamente producido mediante la exigencia de una apariencia de normalidad del servicio, contraria, como ya hemos señalado, al derecho de huelga". Se trataría ésta de una información que puede ser emitida con posterioridad a la jornada de huelga, sin que ello suponga un menoscabo del derecho a comunicar o recibir información, al estar desprovista ésta, por su propia condición de pregrabada, de la actualidad e inmediatez necesarias que pudieran justificar en principio la restricción del derecho de huelga.

Se entiende que la acción de una huelga implica necesariamente la interrupción de los servicios, y que la imposición de una programación continuada durante los horarios habituales de emisión implica una grave vulneración del derecho fundamental ${ }^{21}$. Y la cuestión resulta más grave por cuanto mediante esta técnica se priva de eficacia a la medida de presión, puesto que la huelga no es visible para la audiencia y no repercute en la contraparte afectada, al mantenerse los niveles habituales de programación y emisión.

Dicho pronunciamiento jurisprudencial sirvió de base en la jurisprudencia sentada por la Sala de lo Contencioso Administrativo del Tribunal Supremo ${ }^{22}$ dictada en casos de fijación de servicios mínimos durante huelgas desarrolladas en el sector de la radiodifusión y televisión ante el intento de mantener una normal programación informativa. Según esta doctrina, la actividad informativa mantenida como servicio mínimo ya comporta de por sí sola, una disminución de la total actividad televisiva o radiofónica de cualquier clase que es desarrollada en condiciones de normalidad, afirmando que: "así debe ser considerado porque sólo así resultará visible a la ciudadanía la perturbación que provoca la huelga en la actividad donde es realizada, y sólo así, también, como la huelga cumple esa virtualidad que le corresponde, según recuerda el Tribunal Constitucional, de actuar como un eficaz medio de presión a través de la exteriorización de los efectos que produce el paro laboral".

Otros argumentos dirigidos a prohibir el "esquirolaje" tecnológico derivan del voto particular formulado por algunos magistrados a la STC n ${ }^{\circ}$ 17/2017 de 2 de febrero, en que la utilización de medios tecnológicos durante la huelga exigió de la prestación de

\footnotetext{
${ }^{21}$ TALENS VISCONTI, E., “Esquirolaje tecnológico: Interrogantes abiertos”, ob. cit. p. 182.

${ }^{22}$ STS de 24 de julio de 2007 (RJ 2007/6909); STS de 27 de julio de 2009 (Rec. ${ }^{\circ}$ 161/2007); STS de 24 de febrero de 2010 (Rec. no 1425/2008); STS de 8 de abril de 2010 (Rec. no 4151/2007).
} 
servicios de trabajadores no huelguistas. El voto particular hace una previa reflexión sobre la conducta de dichos trabajadores y sobre el "esquirolaje" interno, que ya fue prohibido en las sentencias del Tribunal Constitucional no 123/1992 y 33/2001, y afirma lo siguiente:

"En efecto, lo que ambos pronunciamientos sostienen es la ilicitud de aquella medida empresarial que, para paliar o minimizar los efectos del ejercicio del constitucional derecho de huelga, encomienda la realización de funciones propias de trabajadores en huelga a trabajadores no huelguistas de un nivel profesional superior al de aquellos". De modo que: "[p]ara apreciar la lesión del derecho de huelga es necesaria la sustitución de los huelguistas "sin causa habilitante para ello" asi como, y tratándose de "sustituciones internas", que el trabajador no sea "asignado de forma irregular a la tarea del huelguista", debiendo entenderse que la sustitución resultará "irregular" en aquellos casos en los que los trabajadores que no secundaron la huelga y, por ende, fueron asignados a las funciones de los que se sumaron a la misma, tengan un "superior nivel profesional".

Estas afirmaciones permiten al voto particular valorar si las prestaciones laborales llevadas a cabo por los trabajadores que no secundaron la huelga pueden o no calificarse como respetuosas con los límites que impone la sustitución interna, y al respecto concluye: "la retransmisión del evento deportivo el día de huelga se articuló e instrumentó mediante la actividad laboral de un trabajador no huelguista cuya categoría excedía con creces la de los trabajadores que optaron por secundar la huelga. O por enunciar la idea en el lenguaje de las SSTC 123/1992 y 33/2011, eludido u ocultado por la presente Sentencia, la sustitución de los trabajadores en huelga se efectuó por otros de superior nivel profesional, medida ésta que tacha de irregular e ilícita la sustitución interna y, por lo mismo, lesiona el constitucional derecho de huelga".

Sentado lo anterior, el voto particular finaliza su exposición denunciado la "deriva hacia una jurisprudencia constitucional cada vez más indiferente con la efectividad de los derechos fundamentales", reiterando: "la creciente preocupación que suscita la doctrina constitucional sobre derechos fundamentales en ámbitos en los que la actuación empresarial restrictiva de su eficacia pretende ampararse, y en todo caso opera, a través de las nuevas tecnologías en el marco de las relaciones laborales" pues: "no es de recibo que la doctrina sobre los derechos fundamentales se muestre del todo insensible y ajena a los cambios tecnológicos, como si en nada estuviera comprometida la Constitución. No puede soslayarse el empleo y los efectos del uso de las nuevas tecnologías por parte del empresario para potenciar sus cauces de vigilancia y control o, como ahora, para lograr una directa repercusión en la efectividad de los derechos 
fundamentales, con finalidad de bloqueo de la finalidad que procura su consagración constitucional".

Afirmando de manera categórica: "[1] as renovadas fuentes de incidencia empresarial en la efectividad de los derechos fundamentales, al amparo de los nuevos medios técnicos a los que recurre para hacer más penetrante su actuación limitativa e impeditiva de la tutela constitucional, requieren respuestas constitucionales también nuevas, que garanticen la protección de los derechos más esenciales de los trabajadores en un grado asimilable al que ofreció nuestra jurisprudencia en el pasado, cuando dichos medios tecnológicos carecían del desarrollo y de la potencialidad restrictiva con los que ahora cuentan. También en esto la Sentencia dictada por el Pleno da la espalda, de manera insensible, a la cobertura constitucional y a la necesidad de adaptarla a las nuevas circunstancias, a la evolución de la realidad laboral por razón de las transformaciones que se producen en el marco de las relaciones de trabajo. Más que una nueva oportunidad perdida, advierto en estos pronunciamientos la repetida confirmación de interpretaciones que eligen la reducción progresiva de la tutela que el contratante débil en la relación laboral precisa de la norma fundamental'.

Si estos son los pronunciamientos más destacables del Tribunal Constitucional, el Tribunal Supremo también ha defendido la prohibición del "esquirolaje" tecnológico, destacando con luz propia los argumentos esgrimidos en el voto particular a la STS de 11 de junio de 2012, y los esgrimidos por la STS de 5 de diciembre de 2012. Ello no quita que exista una diferencia entre la doctrina sentada por el Tribunal Constitucional y la acogida por el Tribunal Supremo. El Tribunal Constitucional analizaba la imposición por el Real Decreto oportuno, de la emisión como servicios mínimos de programas previamente grabados, mientras que el Tribunal Supremo analiza dicha práctica sin esa imposición por la norma reglamentaria, al ser el empresario, quien la impone en virtud de sus facultades organizativas dimanantes de su libertad de empresa ${ }^{23}$.

Según el voto particular a la STS de 11 de junio de $2012^{24}$, permitir el "esquirolaje" tecnológico supone hace una ponderación inadecuada del alcance de los dos derechos constitucionales en presencia: el derecho fundamental de huelga consagrado en el artículo 28.2 de la CE (que, por su ubicación en la Sección $1^{\text {a }}$ del Capítulo II, debe considerarse prevalente), y la libertad de empresa que se reconoce en el artículo 38 de la CE (ubicado en la Sección $2^{a}$ de dicho Capítulo II). En virtud de esa ponderación inadecuada, el derecho de huelga puede llegar a constreñirse hasta extremos que le

\footnotetext{
${ }^{23}$ LÓPEZ LLUCH, I., "El derecho de huelga: Nueva doctrina sobre el "esquirolaje tecnológico" en la sentencia del Tribunal Supremo de fecha 5 de Diciembre de 2012". Aranzadi Social: Revista Doctrinal, vol. $6, \mathrm{n}^{\circ} 5,2013$, p. 15 y ss.

${ }^{24}$ Rec. $n^{\circ} 110 / 2011$.
} 
hagan prácticamente ineficaz en su ejercicio, al amparo de una protección ilimitada de la libertad empresarial. No otra cosa significa, la conclusión radical de que el derecho de huelga "solo se vulnera si los trabajadores asignados a la prestación de servicios mínimos se utilizan para cumplir servicios no esenciales, pero no si los servicios no esenciales se ejecutan por trabajadores no huelguistas o por medios automáticos".

Como indica el propio voto particular: "[d] e hecho la propia STC n $n^{\circ} 123 / 1992$, afirma en su fundamento jurídico quinto que: "el derecho de huelga, que hemos calificado ya como subjetivo por su contenido y fundamental por su configuración constitucional, goza además de una singular preeminencia por su más intensa protección. En efecto, la Constitución reconoce en su artículo 37 el derecho de los trabajadores y empresarios a adoptar medidas de conflicto colectivo, pero desgaja de este marco general una de ellas, la huelga, para colocarlo en lugar preferente, el artículo 28, confiriéndole (como a todos los de su grupo) una mayor consistencia que se refleja en el mayor rango exigible para la Ley que lo regule y en la más completa tutela jurisdiccional, con un cauce procesal "ad hoc" en la vía judicial ordinaria y el recurso de amparo ante nosotros (arts. 53, 81 y 161 CE). La preeminencia de este derecho produce, durante su ejercicio, el efecto de reducir y en cierto modo anestesiar, paralizar o mantener en una vida vegetativa, latente, otros derechos que en situaciones de normalidad pueden y deben desplegar toda su capacidad potencial. Tal sucede con la potestad directiva del empresario, regulada en el artículo 20 del Estatuto de los Trabajadores". Y concluye: "[s]i ello es así con el "esquirolaje” interno, a idéntica conclusión cabría llegar con el tecnológico, si no respeta esa preeminencia del derecho fundamental de huelga ni si se limitan adecuadamente las potestades empresariales en un contexto de no normalidad como el que se deriva del ejercicio de ese derecho, de acuerdo con la doctrina constitucional que se acaba de citar".

Y sigue señalando: "[c]on tal planteamiento, quedaría legitimada una actuación empresarial en el sector audiovisual en la que, en lugar de emitir solamente publicidad, se emitieran también todos los programas de entretenimiento (películas, concursos, reportajes, etc. etc.) que constituyen el mayor porcentaje de la parrilla de programas de cualquier televisión y que están, en su inmensa mayoría pregrabados. Si a ello le añadimos la emisión en directo de los informativos (que siempre estará justificada por el debido respeto al derecho de comunicación e información y así se habrá establecido en la correspondiente norma de servicios mínimos) el resultado práctico no puede ser más evidente: la realización de una huelga en este tipo de empresas puede llegar a tener una trascendencia social prácticamente nula y, consiguientemente, el ejercicio de ese derecho puede quedar casi vaciado de contenido real, especialmente en un tipo de huelgas en las que no se trata de infligir un daño económico al empresario (que, probablemente, tampoco se le produciría si se le permite emitir publicidad) sino de 
hacer visible una protesta contra determinadas medidas gubernamentales que afectan al conjunto de la clase trabajadora" ${ }^{25}$.

Según el voto particular, ello se desprende también de la doctrina constitucional sentada en la STC nº 183/2006, de 19 de junio (a la que hemos hecho referencia anteriormente), conforme a la cual, la posibilidad de limitar los efectos prácticos del ejercicio del derecho de huelga debe ser interpretada restrictivamente, haciendo prevalecer el criterio de la máxima efectividad del derecho fundamental en juego. Pero también se desprendería de la doctrina contenida en la STC n $123 / 1992$, de 28 de septiembre ya citada, donde se abordó un supuesto de "esquirolaje interno". A juicio del voto particular, este es un punto fundamental, ya que, según el Tribunal Constitucional, la legitimidad del "esquirolaje" interno no puede extraerse sin más a partir de una interpretación a "contrario sensu" de la prohibición explícita del "esquirolaje" externo contenida en la ley y conforme a la cual, aquello que no está prohibido, está permitido. Además, el Tribunal Constitucional también afirmó en dicha sentencia que tampoco cabe amparar esa sustitución de los huelguistas en la potestad directiva del empresario (habida cuenta de que se utilizaron trabajadores de otras categorías profesionales) porque: "[e]stos aspectos de la potestad directiva del empresario están imaginados para situaciones corrientes o excepcionales, incluso como medidas de emergencia, pero siempre en un contexto de normalidad con un desarrollo pacífico de la relación laboral, al margen de cualquier conflicto. Por ello puede afirmarse que están en la fisiología de esa relación jurídica, no en su patología".

A juicio del voto particular, estas son las dos claves interpretativas que deben utilizarse para resolver el problema del "esquirolaje tecnológico" en un sentido opuesto al de permitirlo: a) que la legitimidad de una actuación limitadora de un derecho fundamental como es la huelga no puede derivarse de una interpretación "sensu contrario" de un precepto legal; y b) que tampoco puede amparase en el ejercicio de potestades directivas que, en definitiva, derivan del principio de libertad de empresa, y que están concebidas y protegidas por el ordenamiento jurídico para "un contexto de normalidad" pero no para una situación de conflicto ${ }^{26}$.

La posterior STS de 5 de diciembre de $2012^{27}$, acoge íntegramente los argumentos esgrimidos en dicho voto particular, y constituye por sí misma, el máximo exponente de

\footnotetext{
${ }^{25}$ Voto particular a la STS de 11 de junio de 2012 (Rec. $\left.n^{\circ} 110 / 2011\right)$.

${ }^{26}$ Voto particular a la STS de 11 de junio de 2012 (Rec. $\left.n^{\circ} 110 / 2011\right)$.

${ }^{27}$ Rec. no $265 / 2011$.
} 
la prohibición del "esquirolaje" tecnológico ${ }^{28}$. En dicho pronunciamiento se señala que es contraria al derecho de huelga la emisión de programas televisivos cuyo contenido excedió de la condición de meramente informativos, que eran los autorizados por la resolución gubernativa. Entiende el Tribunal Supremo que la emisión de forma automática de publicidad preprogramada puede vulnerar el derecho de huelga, aunque no se utilicen trabajadores para ello (y se efectúe mediante la utilización de medios mecánicos o tecnológicos), si dicha actividad empresarial, priva materialmente a los trabajadores de su derecho fundamental vaciando su contenido esencial. A través de dicha sentencia (cuyo supuesto de hecho es sustancialmente igual al de la STS de 11 de junio de 2012), el alto Tribunal sienta una doctrina acerca del uso empresarial de los instrumentos técnicos durante la huelga, dirigiéndola hacia posiciones más acordes con la eficacia que la CE garantiza a los derechos fundamentales ${ }^{29}$.

La argumentación sentada por la Sala de lo Social del Tribunal Supremo es la siguiente: "[n]o sólo en el supuesto de que se utilicen medios humanos (trabajadores asignados a la prestación de servicios mínimos) para la realización de actividades que exceden de los servicios decretados como esenciales, se lesiona el derecho de huelga, sino que también se lesiona este derecho cuando una empresa del sector de radiodifusión sonora y televisión emite programación o publicidad por medios automáticos, en el caso de que dicha actividad empresarial, aun cuando sea mediante la utilización de medios mecánicos o tecnológicos, priva materialmente a los trabajadores de su derecho fundamental, vaciando su contenido esencial de manera que no cabe el uso de las prerrogativas empresariales, aun amparadas en la libertad de empresa, para impedir la eficacia del derecho de huelga, y ello por la propia naturaleza de este derecho y también de libertad de empresa, que no incorpora a su contenido facultades de reacción frente al paro".

Dicho esto, acaba reproduciendo literalmente los argumentos esgrimidos en el voto particular a la STS de 11 de junio de 2012, de modo que aunque es cierto que el derecho constitucional de huelga no es un derecho absoluto, y que cuando se trata de servicios públicos (como puede ser la televisión) han de mantenerse las garantías necesarias para sostener los servicios esenciales de la comunidad (entre los que se encuentra el derecho a recibir la información, tutelado en el artículo 20.1,d) de la CE), esta limitación no puede enervar aquel derecho constitucional del trabajador, el cual quedaría vacío de

\footnotetext{
${ }^{28}$ Lo que lleva al Tribunal Supremo a modificar la doctrina sentada hasta entonces en las sentencias de 4 de julio de 2000 (Rec. no 75/2000); 9 de diciembre de 2003 (Rec. no 41/2003), 15 de abril de 2005 (Rec. $n^{\text {o }}$ 133/2004), y en la sentencia de 11 de junio de 2012 (Rec. no 110/2011).

29 PEREZ REY, J., "El esquirolaje tecnológico: un importante cambio de rumbo de la doctrina del Tribunal Supremo (STS de 5 de diciembre de 2012)”, ob. cit. p. 163.
} 
contenido, si durante el período de huelga, se pudieran emitir y mantener, no sólo informativos, sino también el resto de la programación habitual.

Y si bien hay ciertos programas que pueden ampararse en el derecho constitucional de informar y comunicar previsto en el artículo 20 de la CE (como los espacios informativos), la mayoría de la programación no reviste el rango amparado por dicho derecho fundamental, sino que está desprovista de todo contenido e interés informativo, revistiendo un carácter, más bien, de puro entretenimiento. De tal modo que el derecho fundamental a la huelga no tiene por qué verse limitado por esta actividad, que puede grabarse y posteriormente programarse para ser emitida sin la intervención de mano de obra durante la huelga, vaciando de contenido a la misma ${ }^{30}$.

Dicha jurisprudencia sentada por el Tribunal Supremo y por el Tribunal Constitucional, también ha sido secundada por la doctrina judicial" ${ }^{31}$, que ha afirmado: "la emisión, dentro de los horarios habituales, de una programación previamente grabada, vulnera el derecho de huelga, al permitir la apariencia de normalidad del servicio, lo que es contrario al derecho de huelga", máxime cuando este conjunto de actuaciones se produce con el ánimo de burlar la repercusión del ejercicio de huelga. En base a ello, los tribunales ordinarios han declarado nulos los decretos de servicios mínimos en cadenas televisivas que preveían la emisión de programas de forma pregrabada, automática y sin necesidad de intervención por trabajadores.

Según dichos pronunciamientos, no se trata tanto de prohibir el uso de medios técnicos automáticos durante la huelga, sino sólo el que se empleen de forma diferente a la habitual y con el propósito de mantener la apariencia de normalidad, aminorando la repercusión de la huelga ${ }^{32}$. De modo que vulnera el derecho de huelga la empresa del sector de la comunicación y prensa escrita que todos los días en que duró la misma, editó el periódico con el mismo número de páginas que con anterioridad, valiéndose de la utilización de medios tecnológicos para la maquetación automática del periódico ${ }^{33}$.

La conclusión que se extrae de estos pronunciamientos jurisprudenciales es que pese a no existir una norma que lo prohíba explícitamente, no parecería difícil sostener que la sustitución "virtual" de los trabajadores en huelga constituye una conducta empresarial ilícita si con ello se pretende restar o privar por completo de efectividad a este derecho

\footnotetext{
${ }^{30}$ TOSCANI GIMÉNEZ, D., "La prohibición de esquirolaje durante la huelga con especial mención al esquirolaje tecnológico", ob. cit. p. 83.

${ }^{31}$ STSJ de Madrid de 2 de marzo de 2011 (AS 2011/1050).

32 STSJ del País Vasco de 22 de febrero de 2011 (Jur 2011/304304); STSJ del País Vasco de 18 de octubre de 2011 (AS 2012/1057); STSJ de Madrid de 4 de junio de 2012 (Rec. no 2633/2012).

${ }^{33}$ STSJ de Extremadura de 29 de abril de 2014 (Rec. n 99/2014).
} 
fundamental. Y es que una cosa es que a través del recurso a los medios técnicos de que dispone la empresa se trate de evitar que la huelga provoque los mayores daños posibles, y otra muy distinta que con ello se persiga una sustitución (encubierta) de los trabajadores huelguistas, neutralizando la capacidad de presión que resulta connatural a la misma.

De hecho, la mayoría de la doctrina científica ${ }^{34}$ se ha decantado por entender que se vulnera el derecho de huelga cuando el empresario utiliza los medios tecnológicos a su alcance con el fin de minorar sus efectos, llegándose a afirmar por algún autor ${ }^{35}$ que el "esquirolaje" tecnológico puede llegar a suponer una involución democrática que erosiona y desvirtúa el alcance y el sentido del derecho fundamental a la huelga.

\section{Las tesis permisivas del "esquirolaje" tecnológico}

Los principales argumentos que han legitimado el uso del "esquirolaje" tecnológico por las empresas, se encuentran en los siguientes pronunciamientos jurisprudenciales: Por parte del Tribunal Supremo en las sentencias de 16 de marzo de 1998, de 27 de septiembre de 1999, de 4 de julio de 2000, de 9 de diciembre de 2003, de 15 de abril de 2005, de 11 de junio de 2012, y de 13 de julio de 2017, y en los votos particulares a la STS de 5 de diciembre de 2012. Y por parte del Tribunal Constitucional, en la STC $\mathbf{n}^{\circ}$ 17/2017 de 2 de febrero. Pasemos a analizarlos.

En las sentencias de 16 de marzo de $1998^{36}$ y de 27 de septiembre de $1999^{37}$, el Tribunal Supremo analiza, especialmente en esta última, un supuesto de sustitución tecnológica, en que, durante una huelga, una cadena televisiva autonómica utilizó la emisión de la señal de otras cadenas para emitir un partido de fútbol sin comentarios y sin inclusión de títulos. A juicio del Tribunal Supremo, la citada actuación empresarial no vulneró el derecho de huelga, pues la recepción y emisión automática de imágenes procedentes del

\footnotetext{
${ }^{34}$ TALENS VISCONTI, E., "Esquirolaje tecnológico: Interrogantes abiertos", ob. cit. p. 186; TODOLI SIGNES, A., "El esquirolaje tecnológico como método de defensa ante una huelga", ob. cit. p. 2 y ss.; LÓPEZ LLUCH, I., "El derecho de huelga: Nueva doctrina sobre el "esquirolaje tecnológico" en la sentencia del Tribunal Supremo de fecha 5 de Diciembre de 2012", ob. cit. p. 151 y ss.; BELTRAN DE HEREDIA, I., "Huelga y esquirolaje interno y técnico: un paso atrás a la luz de la STC 2/2/2017", Revista de Derecho VLex, no 154, Marzo 2017, p. 1 y ss.; PEREZ REY, J., "El Tribunal Constitucional ante el esquirolaje tecnológico (o que la huelga no impida ver el fútbol)", Revista de Derecho Social, $\mathrm{n}^{\circ} 77$, 2017, p. 151 y ss.; SIRVENT HERNANDEZ, N., "La vulneración empresarial del derecho de huelga y responsabilidad por daños y perjuicios", ob. cit. p.149.

${ }^{35}$ BAYLOS GRAU, A., "Pérdida de la función y eficacia de la huelga, especialmente en los sectores de la información y de la telecomunicación. A propósito de las consecuencias de la huelga general de 20 de junio de 2002", Revista General de Derecho del Trabajo y de la Seguridad Social n 5, 2004, p. 2 y ss.

${ }^{36}$ Rec. no $1884 / 1997$.

${ }^{37}$ Rec. $n^{\circ} 1825 / 1998$.
} 
centro de comunicaciones sin intervención de trabajadores de ninguna clase, no supuso una sustitución de trabajadores huelguistas por otros no vinculados a la empresa, prohibida en el artículo 6.5 del RDLRT 17/1977. Con ello el Tribunal supremo opta por una interpretación literal y formalista del término "sustitución", dentro del cual no parece posible enmarcar la suplantación, aun parcial, del hombre por la máquina.

En definitiva: la captación o interceptación de imágenes como consecuencia de una programación previa, no vulnera ni real ni virtualmente el ejercicio del derecho de huelga, pues la sustitución requiere de la intervención de trabajadores, lo que no se produjo, dado que la retransmisión del encuentro por una empresa distinta fue fruto del acuerdo entre otras cadenas de televisión no afectadas por la huelga, por lo que dicha retransmisión no puede considerarse sustitución. De otra parte, la captación de la imagen por la empresa afectada por la huelga tampoco se enmarca en el concepto de sustitución en tanto dicha recepción se produce de modo automático, como consecuencia del nivel técnico alcanzado por la empresa. Y es evidente que la emisión de imágenes por la empresa implica, cuando menos, una voluntad de ofrecer a los usuarios, la parte del servicio que puede seguir prestando sin lesionar el derecho de huelga. Esta voluntad y este resultado son, a juicio del Tribunal Supremo, perfectamente legítimos, pues se enmarcan en el conjunto de medidas activas de que puede hacer uso la empresa, dentro del debido respeto al derecho fundamental de huelga ${ }^{38}$.

En el supuesto de hecho de la STS de 4 de julio de $2000^{39}$, se convocó una huelga en emisoras de radiodifusión, pero los medios técnicos con los que contaba la empresa le permitió mantener de forma automatizada la emisión en antena de programas o música grabada sin intervención de personal, por lo que ni siquiera fue necesaria la sustitución de trabajadores. En dicha sentencia el Tribunal Supremo defiende la licitud del "esquirolaje" tecnológico, señalando que, pese a que la huelga es un derecho fundamental de los trabajadores amparado y reconocido por el artículo 28.2 de nuestra Constitución, y aparece configurado como una presión legal al empresario que debe soportar las consecuencias naturales de su ejercicio por parte de los trabajadores que se abstienen de trabajar, no se impone el deber o la obligación del empresario de colaborar con los huelguistas en el logro de sus propósitos.

Es decir, a juicio del Tribunal Supremo, la ley impide al empresario la sustitución de los trabajadores huelguistas por trabajadores externos (art. 6.5 del RDLRT 17/1977). Y la interpretación jurisprudencial de este mandato le restringe el uso de las facultades de organización que le son propias, en orden a exigir la movilidad funcional ${ }^{40}$. Pero afirma

\footnotetext{
${ }^{38}$ MARTIN JIMENEZ, R., "Sustitución virtual de trabajadores en huelga”, ob. cit. p. 797 y ss.

${ }^{39}$ Rec. $\mathrm{n}^{\mathrm{o}} 75 / 2000$.

${ }^{40}$ STC 123/1992, de 28 de septiembre, y STC 33/2011, de 28 de marzo.
} 
la sentencia: "no hay precepto alguno que prohíba al empresario usar los medios técnicos de los que habitualmente dispone en la empresa, para atenuar las consecuencias de la huelga". De modo que, si los trabajadores participan en la huelga, pero las emisiones no son interrumpidas, y los huelguistas no son sustituidos por otros trabajadores (extraños a la empresa, ni de su propia plantilla), el derecho fundamental no se habría vulnerado. El derecho a la huelga "garantiza el que los huelguistas puedan realizar los paros sin ser sancionados por ello, pero no asegura su éxito, ni en el logro de los objetivos pretendidos, ni en el de conseguir el cese total de la actividad empresarial'.

La tesis defendida en la sentencia reivindica un área de ejercicio del poder empresarial que resulta intangible, porque, se argumenta, no es estamos ante un poder empresarial sobre los trabajadores, sino ante unas facultades que el empresario tiene en exclusiva para organizar el proceso productivo y los instrumentos técnicos para ponerlo en práctica. La línea argumentativa del Tribunal Supremo insiste en la absoluta y total libertad en la disposición técnica del proceso productivo por parte del empresario, con independencia de cuáles sean las consecuencias del mismo, puesto que no cabe exigir al titular de los medios técnicos de producción, la "colaboración" con los titulares del derecho de huelga, para lograr su eficacia. Y este complejo de facultades estrictamente "técnicas", podrían ser indirectamente empleadas para debilitar, socavar o impedir las consecuencias de la huelga, es decir, con la finalidad de vaciar de contenido el derecho fundamental.

En el mismo sentido, se pronunciaron posteriores sentencias del Tribunal Supremo, insistiendo en que el empleo de medios técnicos para asegurar un resultado que palie las consecuencias de la huelga no es una actividad represiva del derecho fundamental. Así, la STS de 9 de diciembre de 2003" , afirma: "la propia característica de la publicidad pone de relieve la ausencia de la actividad propia de una cadena de televisión y compatibiliza el derecho fundamental de huelga, con el derecho de continuidad de la actividad empresarial en términos adecuados", y la STS de 15 de abril de $2005^{42}$ considera compatible con el derecho de huelga que una televisión acudiera, mediante sus recursos tecnológicos, a los colaboradores ordinarios en los servicios informativos, incluidas agencias de noticias ajenas a la empresa que cubrían esta actividad con regularidad y habitualidad.

Como puede comprobarse, esta primera jurisprudencia del Tribunal Supremo legitima la utilización de los medios técnicos propios de la empresa para dar continuidad a la actividad empresarial durante la huelga, sin distinguir entre si su utilización es para

\footnotetext{
${ }^{41}$ Rec. $n^{\circ} 41 / 2003$.

${ }^{42}$ Rec. $n^{\circ} 133 / 2004$.
} 
asegurar los servicios esenciales (mayormente informativos) o lo es para toda la programación.

En la posterior STS de 11 de junio de $2012^{43}$ el Tribunal Supremo da validez al "esquirolaje" tecnológico efectuado por la empresa, consistente en emitir durante la jornada de huelga y de forma automática y sin intervención humana, publicidad y otros contenidos comerciales programados ${ }^{44}$. Esta sentencia, se distancia de la jurisprudencia sentada por el Tribunal Constitucional en su STC n 183/2006 de 19 de junio que había prohibido el "esquirolaje" tecnológico, marcando diferencias respecto de la misma, al afirmar que: "no estamos ente el supuesto que contemplan estas sentencias, porque aquí, no se ha considerado como servicio esencial la emisión de publicidad preprogramada, sino que simplemente se ha procedido a la emisión de la misma, sin que conste que para ello se hayan utilizado los servicios del personal designado para cubrir los servicios esenciales. Por el contrario, se ha probado que la emisión se produjo de manera completamente automática".

A juicio del Tribunal Supremo, la emisión de publicidad preprogramada de forma automática y sin recurrir al personal designado para cubrir los servicios esenciales no lesionaría el derecho de huelga: "porque lo que veda la doctrina del Tribunal Constitucional es que se califique como servicio esencial y que, por tanto, pueda ser atendida por trabajadores asignados a estos servicios (por ejemplo, en labores de control, conexión o supervisión) la gestión de una programación pregrabada que no tiene valor informativo alguno y que, sin embargo, al emitirse, crea la imagen de una continuidad del servicio, y puede perjudicar los objetivos de la huelga. Pero tratándose de una actividad no calificable como de servicio esencial, la misma puede ser realizada por la empresa como cualquier otra actividad, siempre que no se asignen a ella trabajadores encargados de los servicios mínimos, por lo que puede realizarse con personal no huelguista o de forma totalmente automática, sin vulnerar con ello el artículo 6.5 del Real Decreto-Ley 17/1977’. Esta argumentación ha sido defendida en pronunciamientos posteriores del Tribunal Supremo ${ }^{45}$.

Pero, como decíamos, los votos particulares de la STS de 5 de diciembre de 2012 también han incidido en la materia a la hora de justificar el "esquirolaje" tecnológico. El

\footnotetext{
${ }^{43}$ Rec. $\mathrm{n}^{\mathrm{o}} 110 / 2011$.

${ }^{44}$ PEREZ REY, J., "Tertulias, reportajes de actualidad y esquirolaje tecnológico en la huelga general (a propósito de la STS de 11 de junio de 2012)", ob. cit. p. 200.

${ }^{45}$ STS de 13 de julio de 2017 (Rec. $n^{\circ}$ 25/2017), señalando que no se da un supuesto de "esquirolaje" tecnológico cuando la empresa principal, contratante del servicio de telefonía (atención de llamadas telefónicas y resolución de averías), utiliza, como es habitual, un dispositivo automático para redistribuir entre los demás contratistas del servicio los requerimientos de llamadas cuando se producen picos de demanda.
} 
primer voto particular efectuado a la STS de 5 de diciembre de 2012 no solamente reitera los argumentos utilizados por esta STS de 11 de junio de 2012, sino que los amplía.

En primer lugar pone de manifiesto que entender que la emisión automática de programas pregrabados lesiona el derecho de huelga, aunque no haya sustitución de huelguistas, supone excederse de la garantía que prevé el artículo 6.5 del RDLRT $17 / 1977$, porque esta garantía se funda (tanto en el "esquirolaje" interno como en el externo), en la existencia de una sustitución de los huelguistas por trabajadores "no vinculados a la empresa en el momento de ser comunicada (la huelga)", o por trabajadores ya vinculados a la empresa antes de la huelga, pero que desempeñaban funciones distintas, bien utilizando las facultades empresariales de movilidad (STC 123/1992) o bien aceptando la prestación de servicios por trabajadores no huelguistas, pero que actúan de forma manifiesta fuera de su ámbito profesional (STC 33/2011) ${ }^{46}$.

Para apreciar la existencia de lesión del derecho de huelga es conceptualmente necesaria la sustitución de los huelguistas, y ello incluso cuando se trata de "esquirolaje" tecnológico, porque sin esa sustitución no se está privando de eficacia conflictiva al cese del trabajador que se ha declarado en huelga. La sustitución es, según el Diccionario de Real Academia de la Lengua Española, la "acción y efecto de sustituir", que, a su vez, supone "poner a una persona o cosa en lugar de otra". Y esquirol es, además, según el mismo diccionario, el que "se presta a realizar el trabajo abandonado por un huelguista". De ahí que la sustitución exija, en primer lugar, que el trabajo desempeñado por un trabajador huelguista se reemplace sin causa habilitante para ello $y$, en segundo lugar, que ese reemplazo o sustitución se realice en el supuesto normal recurriendo a un trabajador contratado ex novo o asignado de forma irregular a la tarea del huelguista.

Pero sin sustitución no opera la garantía, y no hay sustitución cuando el trabajo sigue realizándose por los mismos trabajadores que no se unen a la huelga, o cuando la actividad productiva (que se realizaba de forma automática sin intervención del trabajo humano) continúa desarrollándose de la misma forma y, por tanto, sin necesidad de reemplazo de la fuerza de trabajo para mantener su continuidad durante la huelga, es decir, cuando no hay huelguistas que hayan sido sustituidos. Y esto último es lo que sucede cuando la actividad continúa desarrollándose a través de procesos automatizados sin intervención de trabajo humano. $\mathrm{Y}$ si bien es cierto que se supone que "algún trabajador al menos tendrá que hacerlos funcionar (los medios mecánicos) o controlar y vigilar su funcionamiento", ésta es una deducción plausible, pero lo cierto es que ese trabajador hipotético no tiene por qué existir, o de existir, no tiene por qué proceder de

\footnotetext{
${ }^{46}$ Primer voto particular a la STS de 5 de diciembre de 2012 (Rec. $\mathrm{n}^{\mathrm{o}}$ 265/2011).
} 
los trabajadores designados para cumplir los servicios mínimos o del "esquirolaje" externo o interno.

En segundo lugar, se afirma que el reconocimiento de la huelga como derecho fundamental, implica el establecimiento de una serie de garantías para evitar que el ejercicio de ese derecho sea restringido o inquietado por determinadas acciones del propio empleador o de terceros. En este sentido se inscriben las previsiones sobre la suspensión del contrato de trabajo durante la huelga, el mantenimiento de la cobertura de la Seguridad Social, la limitación del cierre patronal de respuesta o la protección administrativa y penal del derecho de huelga (art. 8.10 de la LISOS y art. 315 del Código Penal).

Dentro de estas medidas de garantía se encuentran las limitaciones en el empleo de trabajadores para sustituir a los huelguistas que contempla el art. 6.5 del RDLRT 17/1977, tal como ha sido interpretado por la doctrina constitucional en las SSTC 123/1992 y 33/2011 ya mencionadas. Este precepto impone al empresario la prohibición de recurrir a la contratación externa de trabajadores o las medidas de movilidad con la finalidad de sustituir a los huelguistas. Pero se excede el ámbito de esta garantía y el propio contenido del derecho fundamental, cuando lo que se sostiene es que la lesión del derecho de huelga se produce también cuando se realiza "una actividad empresarial aun cuando sea mediante la utilización de medios mecánicos y tecnológicos" y ello, aunque no conste ni la sustitución de huelguistas por esos medios automáticos, ni que tales medios se hayan incorporado a la empresa con la finalidad específica de hacer frente a la huelga.

La única justificación para considerar vulnerado el derecho fundamental es que mediante el empleo de estos medios "se consigue ofrecer una apariencia de normalidad, con lo que la realización de la huelga en este tipo de empresas puede llegar a tener una transcendencia social prácticamente nula y consiguientemente el ejercicio de ese derecho puede quedar prácticamente vaciado de contenido real". Pero, de esta forma, la garantía ya no afecta a la sustitución de los huelguistas, sino al resultado de la huelga, convirtiéndose en una garantía del éxito de ésta, para lo que se impone al empresario una obligación de colaborar a ese resultado, absteniéndose de realizar su actividad por medios que no se ha acreditado que supongan sustitución alguna de los huelguistas ${ }^{47}$. Lo que garantiza la Constitución es el derecho a realizar la huelga, es decir, a cesar temporalmente en el trabajo como medida de presión. No garantiza el resultado positivo de la misma. Dicho más claramente: el derecho de huelga no comprende la obligación de que el empresario se abstenga de realizar una actividad

\footnotetext{
${ }^{47}$ Primer voto particular a la STS de 5 de diciembre de 2012 (Rec. $\mathrm{n}^{\mathrm{o}}$ 265/2011).
} 
productiva que pueda comprometer el logro de los objetivos de la huelga, cuando esa actividad se realiza sin sustitución de los huelguistas.

Y siendo ello así, el problema del "esquirolaje" tecnológico sería más complejo, porque en él habría que distinguir al menos dos situaciones: $1^{\text {a }}$ ) la utilización de medios ya existentes en la empresa para el mantenimiento de determinadas actividades automatizadas sin sustitución de los huelguistas y sin empleo de trabajadores afectados a los servicios mínimos cuando esas actividades no tienen ese carácter; $2^{\mathrm{a}}$ ) la utilización de esos medios para sustituir a los huelguistas, con dos variantes: (a) el empleo para esa finalidad de medios ya existentes en la empresa y (b) la adquisición de esos medios para hacer frente a los problemas planteados por la huelga. Solo en esta segunda situación cabría plantear el problema de la compatibilidad con el derecho de huelga y su extensión por vía analógica a partir del artículo 6.5 del RDLRT 17/1977 ${ }^{48}$.

El segundo voto particular, inicia la argumentación valorando la operación hermenéutica contenida en la sentencia conforme a la cual, puede constituir lesión del derecho de huelga no solamente la sustitución de trabajadores huelguistas sino también la emisión de programas pregrabados en cuya inserción no haya habido intervención alguna de trabajadores en huelga, en lo que sería una interpretación analógica del artículo 6.5 del RDLRT 17/1977. Según el voto particular en esta interpretación analógica postulada, faltan los dos presupuestos exigidos por el artículo 4.1 del Código Civil que prevé este tipo de interpretaciones para aquellos casos en que las normas " $n o$ contemplan un supuesto específico, pero regulan otro semejante entre los que se aprecie identidad de razón", que son: la existencia de una laguna legal y la presencia en el ordenamiento de una norma semejante.

En primer lugar, no existe laguna legal en el caso, en cuanto que el principio de libertad de empresa y el derecho constitucional del empresario a adoptar medidas de conflicto colectivo ya prevén restricciones de la libertad de acción del empresario en supuestos conflictivos. Y, en segundo lugar, no hay identidad de razón entre la prohibición de la sustitución de trabajadores huelguistas y la prohibición de emisión de programas pregrabados, en cuanto que la primera se refiere al mismo factor de producción que la huelga (el "capital humano"), mientras que la segunda pone en juego un factor o medo de producción netamente distinto (el "capital material y tecnológico") de libre disposición por parte de la empresa. La huelga se refiere al trabajo humano y no al funcionamiento de máquinas de titularidad del empresario y a disposición del mismo.

Por otra parte, de acuerdo con la STC $n^{\circ} 11 / 1981$, de 8 de abril, el derecho de huelga es un derecho individual de los trabajadores huelguistas, los cuales no pueden pretender ni

\footnotetext{
${ }^{48}$ Primer voto particular a la STS de 5 de diciembre de 2012 (Rec. $n^{\text {o }}$ 265/2011).
} 
que se sumen a su ejercicio los no huelguistas, ni que el empresario al que va dirigida la presión huelguística colabore por inacción u omisión al éxito de la medida singular de conflicto colectivo en que la huelga consiste. A ello hay que añadir que la huelga es un derecho instrumental y no un derecho absoluto, que ha de convivir en el ordenamiento de los conflictos colectivos de trabajo con el derecho del empresario a adoptar medidas efectivas de conflicto colectivo.

Ciertamente, algunas de las medidas de conflicto colectivo del empresario están restringidas o limitadas por el legislador, que ha dispuesto la desigualdad de armas de los contendientes en este ámbito particular de la competición entre las fuerzas productivas. Pero en la relación de las restricciones o limitaciones de las medidas de conflicto colectivo de los empresarios no se encuentran los actos empresariales de mantenimiento de la producción sin intervención humana, los cuales están respaldados de un lado por el derecho a la libertad de empresa en su vertiente de ejercicio de actividades empresariales lícitas, y de otro lado por la defensa de la productividad que el artículo 38 de la CE encarga expresamente a los poderes públicos, incluidos los organismos jurisdiccionales.

Pero este voto particular precisa que tampoco cabe entender que el "esquirolaje" tecnológico vulnere el derecho de huelga sobre la base de otros dos argumentos ${ }^{49}$ :

El primero de ellos es que la ubicación sistemática del derecho de huelga en una posición destacada dentro de los "derechos y libertades" constitucionales (sección $1^{\text {a }}$ del capítulo II CE) le atribuye un rango o posición preeminente respecto de otros derechos o intereses, como son el derecho al trabajo, o el interés de los empresarios y de la economía en general en "la defensa de la productividad" (artículo 38 de la CE). Pero se trata de un argumento desenfocado, porque si bien es verdad que el artículo 53 de la CE otorga al derecho de huelga una protección jurisdiccional reforzada, la disposición de vías jurídicas de defensa de especial efectividad no quiere decir que los intereses jurídicos protegidos de los huelguistas tengan mayor consideración o dignidad "sustantiva" que los de los demás afectados (trabajadores no huelguistas, empresarios, usuarios de servicios públicos, etc.), sino tan solo que las especiales características del ejercicio de la huelga han aconsejado una protección jurisdiccional dotada de la mayor eficacia procesal posible. La fragilidad o vulnerabilidad del ejercicio del derecho de huelga no es en la actualidad predicable con carácter general, y de hecho en las huelgas político-económicas de "protesta", puede y suele ser más frágil o vulnerable el ejercicio de la libertad de trabajo o el ejercicio de los derechos de los ciudadanos afectados por las alteraciones derivadas de la huelga (derechos cuyo reconocimiento y protección

\footnotetext{
${ }^{49}$ Segundo voto particular a la STS de 5 de diciembre de 2012 (Rec. $\mathrm{n}^{\circ}$ 265/2011).
} 
constan también expresamente en la Constitución y en la normativa legal del derecho de huelga) que el propio derecho de huelga.

El segundo es que los derechos a compaginar o armonizar no son únicamente el derecho de huelga y la libertad de empresa, sino también, junto con los anteriores, el derecho constitucional de trabajadores y empresarios a adoptar medidas de conflicto colectivo, dentro de las cuales se encuentran todas aquellas que no hayan sido limitadas o excluidas por la ley que regule el ejercicio de este derecho (artículo 37.2 de la CE). El RDLRT 17/1977 incluye ciertamente limitaciones importantes de la conducta del empresario durante la huelga, entre las que se encuentra en lugar destacado la prohibición de sustitución de los trabajadores huelguistas. Pero el RDLRT ni obliga a los restantes trabajadores a contribuir con el éxito de la reivindicación o de la protesta (y de hecho se ha de respetar la libertad de trabajo de aquellos trabajadores que no quisieran sumarse a la huelga "ex" artículo 6.4 del RDLRT), ni con mayor razón obliga al empresario a reducir la actividad empresarial más allá del seguimiento que la declaración de huelga haya podido tener en el colectivo afectado.

Si estos han sido los argumentos del Tribunal Supremo, la reciente sentencia del Tribunal Constitucional $n^{\circ}$ 17/2017 de 2 de febrero, ha incidido decisivamente en la materia, al permitir el "esquirolaje" tecnológico, no solamente cuando la empresa utiliza medios automáticos preexistentes no habituales y sin intervención humana, sino también cuando utiliza a trabajadores no huelguistas que los puedan gestionar ${ }^{50}$. En el caso debatido en ella, la empresa utilizó medios técnicos de los que disponía, y de uso no habitual, para retransmitir un partido de fútbol el día de la huelga, y para ello se sirvió de trabajadores no huelguistas que siguieron realizando las funciones propias de su categoría profesional.

Según el Tribunal Constitucional, el reconocimiento del derecho de huelga implica el establecimiento de una serie de garantías para evitar que el ejercicio de ese derecho sea restringido por determinadas acciones del propio empresario. De este modo, el RDLRT 17/1977 incluye importantes limitaciones de la conducta del empresario durante la huelga, entre las que se encuentra la prohibición de sustitución de trabajadores huelguistas por otros no pertenecientes a la empresa (art. 6.5 RDLRT). Y las SSTC n ${ }^{\circ}$ 123/1992 y 33/2011, atendiendo al objetivo inspirador del artículo 6.5 RDLRT, también

\footnotetext{
${ }^{50}$ Ver el comentario a esta sentencia de: BELTRAN DE HEREDIA, I., "Huelga y esquirolaje interno y técnico: un paso atrás a la luz de la STC 2/2/2017", ob. cit. p. 1 y ss.; GARCÍA PERROTE ESCARTIN, I., "Los límites de la sustitución virtual de trabajadores y del recurso a procesos de descentralización durante la huelga en la doctrina reciente del Tribunal Constitucional y del Tribunal Supremo", Revista de Información Laboral $\mathrm{n}^{\circ}$ 6, 2017, p. 2 y ss.
} 
habrían considerado que constituye un ejercicio abusivo del "ius variandi" del empresario, la sustitución interna de los trabajadores huelguistas durante la huelga.

Sin embargo, a juicio del Tribunal Constitucional, en el supuesto debatido, la empresa no había contratado a otros trabajadores para realizar las funciones de los huelguistas, ni el empresario había modificado las funciones que venían realizando los no huelguistas. Es decir, no se estaba ante el ejercicio del "ius variandi" que corresponde al empresario (pues los no huelguistas no desarrollaron funciones distintas de las que tenían asignadas), sino ante el ejercicio del poder de organización de los medios de producción con los que se cuenta en la empresa.

La duda que se plantea es si la utilización de medios técnicos de los que dispone la empresa, pero que no utiliza con carácter habitual, constituye una vulneración del derecho de huelga y puede asimilarse a los supuestos de "esquirolaje" o sustitución de los trabajadores huelguistas, y en este sentido, el alto Tribunal ya adelanta que no existe en los ordenamientos de nuestro entorno ninguna previsión que ampare una lectura del derecho de huelga que abarque lo que aquí se pretende ${ }^{51}$.

En base a ello el Tribunal Constitucional señala: "[n] o hay duda de que la libertad del empresario, por lo que respecta a sus facultades de organización y dirección de los trabajadores, queda restringida por el ejercicio del derecho de huelga, mas no hay precepto alguno que, durante este ejercicio, prohíba al empresario usar los medios técnicos de los que habitualmente dispone en la empresa para mantener su actividad. Una actividad que, como se ha dicho, es inherente a la lesividad del ejercicio de la huelga e instrumental al ejercicio del derecho al trabajo de aquellos trabajadores que han decidido no sumarse a la misma". Y añade: "[d]e otra parte, exigir al empresario que no utilice medios técnicos con los que cuenta en la empresa supone imponer al empresario una conducta de colaboración en la huelga no prevista legalmente. La utilización de medios ya existentes en la empresa es compatible con el derecho de huelga y no puede extenderse, por vía analógica a este supuesto, la prohibición prevista en el artículo 6.5 RDLRT, que se refiere al empleo de los recursos humanos en la empresa, pero no a la utilización de sus recursos materiales y tecnológicos".

En esta lógica argumental, el Tribunal Constitucional sigue afirmando: "[e]l respeto al contenido esencial del derecho de huelga comporta limitaciones importantes de la conducta del empresario durante la huelga, entre las que se encuentra, la prohibición de sustitución de los trabajadores huelguistas (art. 6.5 RDLRT). Pero ni la Constitución ni la jurisprudencia constitucional obligan a los restantes trabajadores a contribuir al éxito de la reivindicación, pues debe respetarse la libertad de trabajo de aquellos

\footnotetext{
${ }^{51}$ Voto particular a la STS de 11 de junio de 2012 (Rec. $\left.n^{\circ} 110 / 2011\right)$.
} 
trabajadores que no quisieran sumarse a la huelga, ni obligan al empresario a reducir la actividad empresarial más allá de lo que sea una consecuencia lógica del seguimiento de la huelga por los trabajadores afectados".

Y concluye: "[1] a efectividad del ejercicio del derecho de huelga no demanda del empresario una conducta dirigida a no utilizar los medios técnicos con los que cuenta en la empresa o a abstenerse de realizar una actividad productiva que pueda comprometer el logro de los objetivos de la huelga, al igual que no obliga a los restantes trabajadores a contribuir al éxito de la protesta, y ello porque lo que garantiza la Constitución es el derecho a realizar la huelga, no el resultado o el éxito de la misma. El empresario tiene que soportar inevitablemente un daño como consecuencia de la huelga derivado de la interrupción de la actividad en que la misma consiste, pero sería desproporcionado exigir al empresario que colabore por inacción u omisión al éxito de la huelga. El derecho de huelga aparece configurado como una presión legal al empresario que debe soportar las consecuencias naturales de su ejercicio por parte de los trabajadores que se abstienen de trabajar, pero no se impone el deber o la obligación de colaboración con los huelguistas en el logro de sus propósitos...Asimismo, la utilización por parte de los trabajadores no huelguistas de los medios técnicos de los que dispone la empresa, sin realizar funciones de una categoría distinta, ha permitido hacer efectiva la libertad de trabajo que les reconoce el artículo 6.4 RDLRT y la jurisprudencia constitucional"52.

Se trata de una sentencia que ha sido objeto de numerosas críticas por parte de la doctrina científica ${ }^{53}$, dado que impide la tutela del derecho de huelga de los trabajadores vaciando de contenido no solo el citado derecho fundamental, sino el mismo modelo constitucional de relaciones laborales acorde con el Estado social y democrático de derecho.

Por de pronto el Tribunal Constitucional, ofrece argumentos que se insertan en la óptica de la legalidad ordinaria al defender la ausencia de preceptos que impidan el empresario usar la infraestructura técnica, sin tener en cuenta cómo decisiones anteriores del propio Tribunal Constitucional habían censurado expresamente esta fórmula de interpretación de los derechos constitucionales.

\footnotetext{
${ }^{52}$ STC 37/1998, de 17 de febrero.

${ }^{53}$ PEREZ REY, J., "El Tribunal Constitucional ante el esquirolaje tecnológico (o que la huelga no impida ver el fútbol)", ob. cit. p. 160; BELTRAN DE HEREDIA, I., "Huelga y esquirolaje interno y técnico: un paso atrás a la luz de la STC 2/2/2017", ob. cit. p. 1 y ss.; TOSCANI GIMÉNEZ, D., "La prohibición de esquirolaje durante la huelga con especial mención al esquirolaje tecnológico", ob. cit. p. 83.
} 
Pero, sobre todo, el supuesto debatido en la sentencia no constituye un caso de "esquirolaje" tecnológico en sentido estricto, o al menos, no se presenta con la pureza con la que aquél se manifiesta (que es la activación productiva empresarial sin intervención de trabajadores) ${ }^{54}$. El rasgo identificador del "esquirolaje" tecnológico es que el empresario, durante la celebración de la huelga, no utiliza recursos humanos, ni externos ni internos. $\mathrm{Y}$ no es este el supuesto que resuelve la sentencia del Tribunal Constitucional, en que los trabajadores no huelguistas decidieron ponerse al mando de medios técnicos para continuar con la actividad productiva.

En sentido estricto, nos encontraríamos ante un "esquirolaje" interno, y no tecnológico, y desde esta perspectiva, la aplicación de la jurisprudencia constitucional preexistente sobre la sustitución interna de trabajadores huelguistas ya hubiera sido suficiente para resolver el problema en un sentido favorable al derecho de huelga ${ }^{55}$. Pero el Tribunal Constitucional lleva a cabo una aplicación selectiva de su propia doctrina sobre el "esquirolaje" interno, evitando aquellos pasajes de la misma que hubieran determinado un pronunciamiento diferente del propuesto.

Y además utiliza el derecho al trabajo de los no huelguistas para justificar la actuación empresarial, afirmando que éstos, al emplear los medios técnicos, no sustituyeron en sentido estricto a los trabajadores huelguistas, conclusión que tampoco es compartible si se tiene en cuenta que la empresa, en realidad, sí alteró el esquema funcional y la división de tareas entre departamentos para aprovechar a los trabajadores que no secundaron el conflicto, en una actuación que se inscribe más en la dinámica del "esquirolaje" interno prohibido que en el del tecnológico ${ }^{56}$.

\section{Conclusiones}

I. El artículo 6.5 del RDLRT 17/1977 de 4 de marzo, señala que en tanto dure la huelga, el empresario no podrá sustituir a los trabajadores huelguistas por otros trabajadores que no estuviesen vinculados a la empresa al tiempo de ser comunicada la misma. Sin embargo, la norma no contempla la utilización por parte del empresario de los medios técnicos que tiene a su disposición para continuar con su actividad productiva durante el desarrollo de una huelga.

\footnotetext{
${ }^{54}$ VIDAL LOPEZ, P., “¿Puede la tecnología suplir a los trabajadores huelguistas? El "esquirolaje como mecanismo ilícito para neutralizar la huelga", Actualidad jurídica Aranzadi, nº 928, 2017, p. 12 y ss.

${ }^{55}$ BELTRAN DE HEREDIA, I., "Huelga y esquirolaje interno y técnico: un paso atrás a la luz de la STC 2/2/2017", ob. cit. p. 1 y ss.

${ }^{56}$ PEREZ REY, J., "El Tribunal Constitucional ante el esquirolaje tecnológico (o que la huelga no impida ver el fútbol)", ob. cit. p. 162.
} 
II. En torno al recurso empresarial a los medios tecnológicos para reemplazar el trabajo de los huelguistas existe un debate doctrinal y jurisprudencial que hunde sus raíces en el conflicto subyacente que existe entre capital y trabajo en el seno de las relaciones laborales. Ante la ausencia de una expresa regulación legal, tanto la jurisprudencia constitucional como la ordinaria han defendido tesis a favor y en contra del llamado "esquirolaje" tecnológico, dejando la cuestión abierta o no zanjada a la espera de una futura legislación sobre el derecho de huelga.

III. La tesis prohibitiva del "esquirolaje" tecnológico, se ampara en tres argumentos. El primero sería de índole interpretativa, según el cual, la permisión del "esquirolaje" tecnológico no puede extraerse sin más de una interpretación en sentido contrario, basada en el hecho de que la legislación no lo prohíbe. Una legislación obsoleta e insuficiente no puede convertirse en un obstáculo para que el derecho de huelga despliegue sus efectos, y el artículo 6.5 del RDLRT 17/1977 debe ser interpretado desde un punto de vista finalista, a la luz de la realidad social actual. Por ello, teniendo en cuenta el contexto y el espíritu y finalidad de la norma (que es la de evitar que se limite el ejercicio del derecho fundamental), el empresario no puede recurrir a los medios tecnológicos para garantizar la actividad productiva durante la huelga.

IV. El segundo argumento es que el derecho de huelga está previsto en el artículo 28.2 de la CE como derecho fundamental, y por su ubicación sistemática debe ser prevalente a la libertad de empresa prevista en el artículo 38, e incluso a la adopción de medidas de conflicto colectivo prevista en el artículo 37. De modo que, ante un eventual conflicto entre el derecho de huelga y la libertad de empresa, es el primero el que ha de prevalecer. En la relación entre el derecho y su límite posible (y qué duda cabe que el respeto a la libertad de empresa es un límite al derecho de huelga) el criterio de interpretación debe ser el de la mayor amplitud posible del derecho y la restricción del límite a lo necesario. Por ello, el "esquirolaje" tecnológico no puede amparase en el ejercicio de potestades directivas derivadas de la libertad de empresa, y que están concebidas y protegidas por el ordenamiento jurídico para un contexto de normalidad, pero no para una situación de conflicto.

V. El tercer argumento es que el contenido esencial del derecho de huelga no se concreta sólo en garantizar la cesación en el trabajo, sino también en la consecución de una cierta eficacia, y si el ejercicio del derecho de huelga trae consigo unos sacrificios que asumen los trabajadores con el objetivo de provocar ciertos perjuicios al empresario, la huelga perdería su eficacia como tal si el empresario pudiera neutralizar dichos efectos mediante el recurso a medios tecnológicos. 
VI. La tesis permisiva del "esquirolaje" tecnológico, por el contrario, se ampara en argumentos opuestos a los anteriores. En primer lugar, se argumenta que no hay precepto alguno que prohíba al empresario durante una huelga, usar los medios técnicos de los que habitualmente dispone para mantener su actividad productiva. De hecho, tampoco existe en los ordenamientos jurídicos de nuestro entorno ninguna previsión que ampare una lectura del derecho de huelga que abarque la limitación del uso de los medios técnicos por parte del empresario. La prohibición prevista en el artículo 6.5 del RDLRT, se refiere al empleo de los recursos humanos en la empresa, pero no a la utilización de sus recursos materiales y tecnológicos, y sólo así se entiende el término "sustitución" empleado por el legislador o la expresión "esquirol". Por ello, la actividad productiva realizada de forma automática durante la huelga, y en la que no intervienen trabajadores, no produce esta situación de reemplazo prohibida.

VII. En segundo argumento se ampara en que el derecho de huelga, pese a su configuración como un derecho fundamental, no impone al empresario un deber $\mathrm{u}$ obligación de colaboración con el resultado de la huelga, máxime cuando durante la misma no se procede a la sustitución de huelguistas y se recurre a los medios tecnológicos disponibles. El derecho de huelga ha de convivir con las medidas de conflicto colectivo que pueda tomar el empresario, debiendo realizarse una ponderación en cada caso concreto, y es que la preeminencia que la Constitución Española reconoce al artículo 28.2 frente al artículo 38, se funda en un reforzamiento o una especial protección basada en la mayor eficacia procesal del derecho fundamental, pero ello no significa que los huelguistas tengan una mayor consideración o dignidad sustantiva respecto al resto de afectados, como son los trabajadores que no secundan la huelga, los empresarios, y los demás usuarios de los servicios.

VIII. Teniendo en cuenta los argumentos esgrimidos por cada una de estas dos tesis, es la primera la que ha de prosperar, como así ha entendido la gran mayoría de la doctrina científica. El ordenamiento jurídico no exige que los empresarios lleven a cabo acciones que potencien o amplifiquen los efectos de la huelga, pero sí les impone la obligación de sufrir los efectos negativos que el ejercicio del derecho de huelga suponga en sus procesos productivos o en los servicios que ofrezcan, sin que puedan adoptar decisiones que disminuyan los efectos negativos de la huelga como mecanismo de presión para la mejora de los derechos de los trabajadores. No cabe el uso de prerrogativas empresariales, aún amparadas en la libertad de empresa, para impedir la eficacia del derecho de huelga, y ello por la propia naturaleza de este derecho y también del de libertad de empresa, que no incorpora a su contenido facultades de reacción frente al paro. Ello excluye la posibilidad de que el empresario pueda atenuar las consecuencias de la huelga mediante el recurso a medios tecnológicos. 
Fecha recepción: 19.10.2018 Fecha aceptación: 18.11.2018 